\title{
The Role of Hemodynamics in Intracranial Bifurcation Arteries after Aneurysm Treatment with Flow-Diverter Stents
}

\author{
(D) A.P. Narata, (DF.S. de Moura, (DI. Larrabide, (D) C.M. Perrault, (DF. Patat, (DR. Bibi, (D) S. Velasco, (D) A.-C. Januel, (D) C. Cognard, \\ (iD) Chapot, (D) A. Bouakaz, (D)C.A. Sennoga, and (iD) A. Marzo
}

\begin{abstract}
BACKGROUND AND PURPOSE: Treatment of intracranial bifurcation aneurysms with flow-diverter stents can lead to caliber changes of the distal vessels in a subacute phase. This study aims to evaluate whether local anatomy and flow disruption induced by flow-diverter stents are associated with vessel caliber changes in intracranial bifurcations.
\end{abstract}

MATERIALS AND METHODS: Radiologic images and demographic data were acquired for 25 patients with bifurcation aneurysms treated with flow-diverter stents. Whisker plots and Mann-Whitney rank sum tests were used to evaluate if anatomic data and caliber changes could be linked. Symmetry/asymmetry were defined as diameter ratio $1=$ symmetric and diameter ratio $<1=$ asymmetric. Computational fluid dynamics was performed on idealized and patient-specific anatomies to evaluate flow changes induced by flow-diverter stents in the jailed vessel.

RESULTS: Statistical analysis identified a marked correspondence between asymmetric bifurcation and caliber change. Symmetry ratios were lower for cases showing narrowing or subacute occlusion (medium daughter vessel diameter ratio $=0.59$ ) compared with cases with posttreatment caliber conservation (medium daughter vessel diameter ratio $=0.95$ ). Computational fluid dynamics analysis in idealized and patientspecific anatomies showed that wall shear stress in the jailed vessel was more affected when flow-diverter stents were deployed in asymmetric bifurcations (diameter ratio $<0.65$ ) and less affected when deployed in symmetric anatomies (diameter ratio $\sim 1.00$ ).

CONCLUSIONS: Anatomic data analysis showed statistically significant correspondence between caliber changes and bifurcation asymmetry characterized by diameter ratio $<0.7(P<.001)$. Similarly, computational fluid dynamics results showed the highest impact on hemodynamics when flow-diverter stents are deployed in asymmetric bifurcations (diameter ratio $<0.65$ ) with noticeable changes on wall sheer stress fields. Further research and clinical validation are necessary to identify all elements involved in vessel caliber changes after flow-diverter stent procedures.

ABBREVIATIONS: DR $=$ daughter vessel diameter ratio; FDS = flow-diverter stent; WSS $=$ wall shear stress

E ndovascular treatment of intracranial aneurysms by using a flow-diverter stent (FDS) is a widely accepted technique for complex proximal aneurysms. The successful use of FDSs in voluminous carotid aneurysms was the motivation for extending this treatment to complex lesions like hemorrhagic vertebral artery dissections, blister aneurysms, and complex MCA aneu-

Received June 20, 2017; accepted after revision October 2

From the University Hospital of Tours (A.P.N., R.B.), Tours, France; Engineering, Modeling, and Applied Social Sciences Center (F.S.d.M.), Federal University of ABC, Santo André, Brazil; PLADEMA-CONICET (I.L.), Universidad Nacional del Centro de la Provincia de Buenos Aires, Tandil, Argentina; Mechanical Engineering Department, INSIGNEO Institute for in Silico Medicine (C.M.P., A.M.), University of Sheffield, Sheffield, United Kingdom; UMR "Imagerie et Cerveau," Inserm U930 (F.P., A.B., C.A.S.), Université Francois Rabelais, Tours, France; University Hospital of Poit iers (S.V.), Poitiers, France; University Hospital of Toulouse (A.-C.J., C.C.), Toulouse, France; and Alfried Krupp Krankenhaus (R.C.), Essen, Germany.

This work was supported by the Newton Programme Fund from the Royal Academy of Engineering, London, United Kingdom.

rysms. ${ }^{1,2}$ From a review of 106 reported cases in which bifurcation aneurysms were treated with FDSs, it was found that the bifurcating branch "jailed" by the stent remained unchanged in 30\%-57\% of cases, narrowing occurred in $29 \%-60.8 \%$ of cases, and occlusion occurred in $8.27 \%-25 \%$ of cases. ${ }^{3-8}$ Although the sample size is relatively small, it is worth noting that nearly two-thirds of jailed arteries were narrower after FDS treatment, which can lead to severe consequences. Depending on collateralization, permanent neurologic impairment can appear after FDS treatment, affecting $0 \%-27 \%$ of patients. MR imaging-positive ischemic lesions were detected in $43 \%-64 \%$ of the patients. ${ }^{4,6}$

\footnotetext{
Please address correspondence to Ana Paula Narata, MD, Service of Neuroradiology, University Hospital of Tours, 2 Blvd Tonnelle, 37000 Tours, France; e-mail: ana-paula.narata@chu-tours.fr

$\equiv$ Indicates article with supplemental on-line table.

Indicates article with supplemental on-line photo

http://dx.doi.org/10.3174/ajnr.A5471
}

AJNR Am J Neuroradiol 39:323-30 Feb 2018 www.ajnr.org 
The reason some branches remain unchanged and others are affected by a narrowing process is unknown. Iosif and colleagues ${ }^{6,9}$ have linked episodes of FDS-induced vessel occlusions with the presence of collateral branches that would increase blood supply to the target tissues when resistance to flow increases in the occluding vessel. This would ultimately lead to the occlusion of the jailed vessel. Supported by animal-model data, this theory proposes collateral blood supply and endothelial cell coverage of the stent at the ostium (where the stent jails the daughter vessel) as a mechanism leading to complete vessel occlusion. However, this would only explain some but not the entire cohort of cases reporting vessel subacute occlusion or narrowing. For instance, the same theory cannot explain why FDS treatment of intracranial aneurysms near the anterior choroidal artery, ophthalmic artery, and some MCA bifurcations, all benefiting from collateral supply, often lead to the successful conservation of patency of the jailed artery. ${ }^{5,10}$ It thus seems that other factors are at play in those cases. Because it is well known that hemodynamics is a key element in endothelial flow-mediated vasodilation and vasoconstriction, we explored hemodynamic disturbance after FDS procedures in idealized and patient-specific anatomies.

\section{MATERIALS AND METHODS}

The research hypothesis is that pretreatment hemodynamics are perturbed in those cases showing partial or complete occlusion of the unstented daughter vessel. The methodology of the study was developed to test this hypothesis and structured within 3 different phases: radiologic data analysis to identify possible associations with clinical outcome in our patient datasets (phase I), idealized geometry computational fluid dynamics study (phase II), and patient-specific computational fluid dynamics study to characterize the influence of FDS on hemodynamics at bifurcations of different types (phase III).

\section{Phase I: Radiologic Data Analysis}

Clinical data were collected cooperatively between the University Hospitals of Tours, Toulouse, and Poitiers, France, and Alfried Krupp Krankenhaus, Germany. A total of 25 patients with bifurcation aneurysms treated with FDSs between December 2010 and December 2015 were identified retrospectively and followed prospectively upon appropriate ethical approval and patient consent. Only anterior communicating artery aneurysms with agenesis of the contralateral anterior cerebral artery, basilar artery aneurysms with bilateral hypoplasia of the posterior communicating arteries, and MCA aneurysms were included.

Radiologic imaging data and clinical outcome at baseline and at 3-month follow-up were obtained from the patient medical records. The On-line Table shows the demographic constitution of the study population along with anatomic information and clinical outcome. Anatomic data represent the average values of measurements performed on the pre-FDS imaging data, which were assessed independently by 3 senior neuroradiologists who were kept unaware of the study outcomes. Three vessel diameter and angle measurements were taken along the initial part of each bifurcating branch, reporting only its arithmetic average value and their standard deviation to quantify interobserver variability. Vessel diameters and angles were measured from 2D acquisitions by digital subtraction angiography and 3D rotational angiography images by using OsiriX (http://www.osirix-viewer.com). The reliability of these measures was assessed with 2-way, mixed intraclass correlation coefficients showing high reliability (intraclass correlation coefficients $[3, \kappa]=0.971)$.

Statistical analysis included the comparison of the daughter vessel diameter ratios (DRs; ratios between smaller and larger diameters) and bifurcating angles for 2 groups: Group A $(n=14)$ included cases where narrowing or subacute occlusion of the jailed artery was observed at 3-month follow-up, and Group B ( $n=11)$ included cases showing no caliber changes of the jailed artery at baseline or 3-month follow-up. Because data were not normally distributed, a Mann-Whitney rank sum test was performed to quantify statistical differences between DR and angle distributions in the 2 groups.

\section{Phase II: Idealized Computational Fluid Dynamics Study}

We created a number of idealized $3 \mathrm{D}$ geometries representative of patient-specific anatomies to allow a controlled analysis of the sensitivity to factors influencing hemodynamics. For all idealized cases, parent vessel diameter was set to $2.51 \mathrm{~mm}$ to represent the average size of the population in the On-line Table. Inlet and outlet lengths were set to 10 and 4 times the parent vessel diameter, respectively.

DR was varied between 0.4 and 1 (DR $=1=$ symmetrical). Mutual bifurcation diameters were defined in accordance with Murray's law, an established theory in biomechanics regulating the relationship of bifurcating vessel diameters and based on minimal energy consumption. ${ }^{11}$

Daughter vessel angles were fixed at $120^{\circ}$, except for some of the symmetric bifurcation cases $(\mathrm{DR}=1)$, in which the angle for only 1 of the bifurcating vessels was set at $60^{\circ}, 90^{\circ}, 120^{\circ}$, and $150^{\circ}$ to capture their effect of the angles on flow distribution across the bifurcation (Fig 1, line iv).

Stents were virtually deployed in the idealized geometries by using an approach previously described by Larrabide et al, ${ }^{12}$ leading to a total of 3 configurations for each bifurcation type (unstented, stented along smaller daughter vessel $d_{1}$, and stented along larger daughter vessel $d_{2}$ ). FDS models represent typical geometries available on the market. In particular, these represent 48 wires ( 24 braids on each direction) and a wire thickness of 0.04 $\mathrm{mm}$. The deployed stent diameter was set to fit the diameter of the parent vessel, ensuring a proper apposition of the FDS to the vessel wall.

Governing equations for steady flow were solved by using ANSYS CFX (ANSYS, Canonsburg, Pennsylvania). Blood was assumed incompressible, with attenuation $\rho=1050 \mathrm{~kg} \times \mathrm{m}^{-3}$, and Newtonian, with viscosity $\mu=0.0035 \mathrm{~Pa} \times \mathrm{s}$. The appropriateness of the modeling approach and computational accuracy were verified based on computational methodologies reported in the literature. ${ }^{13,14}$ Fully developed parabolic velocity profiles were imposed at inlet boundaries, resulting in typical volumetric flow rates at peak systole and end diastole $\left(\mathrm{Q}_{\text {sys }}=3.71 \mathrm{~mL} / \mathrm{s} ; \mathrm{Q}_{\mathrm{dia}}=\right.$ $0.98 \mathrm{~mL} / \mathrm{s}$ ). ${ }^{15}$ Outlet boundaries were set to mimic typical resistance to flow from the peripheral beds, and their values were derived from predicted values of pressure and volumetric flow data obtained with the 1D model developed and validated by Rey- 


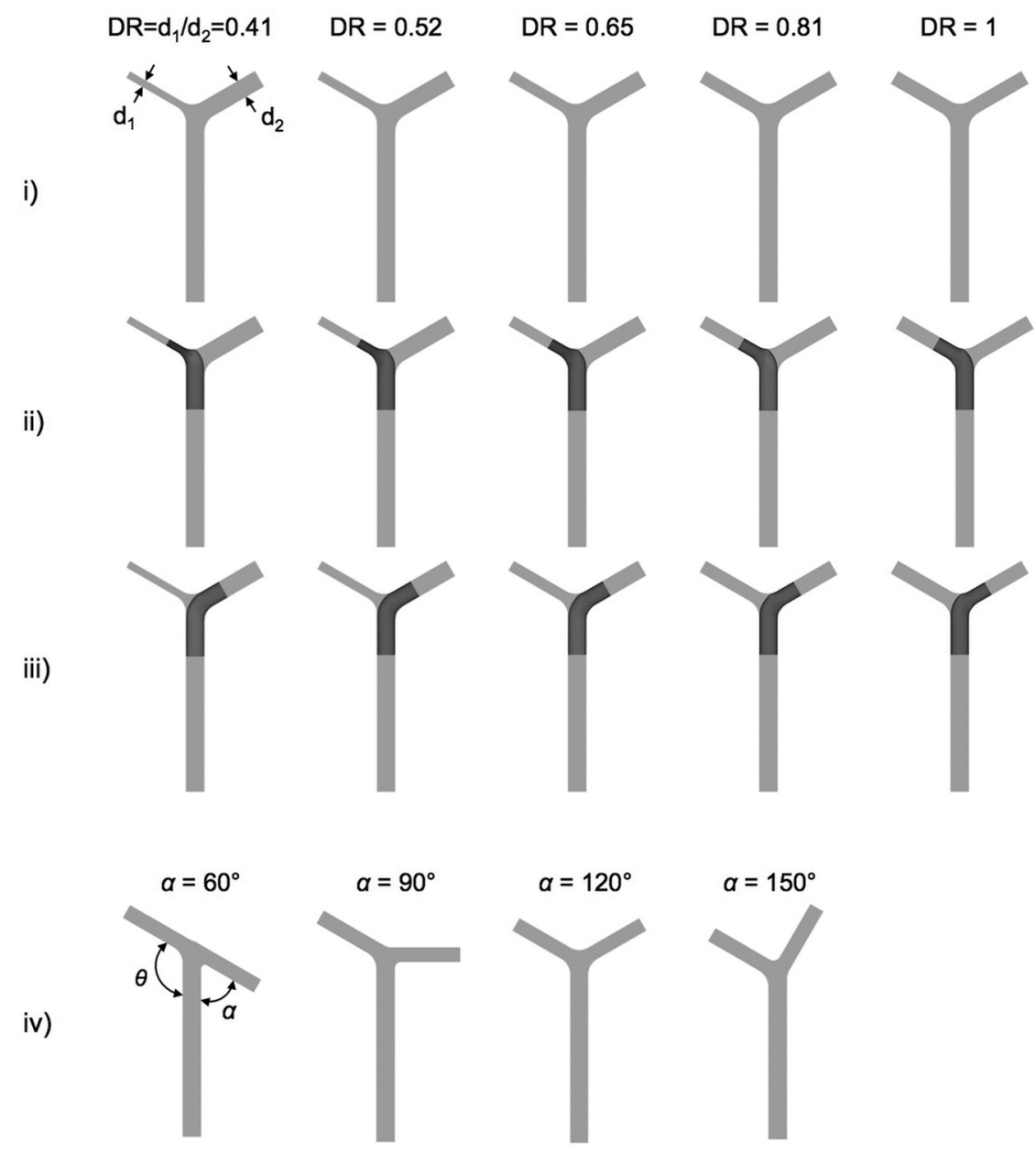

FIG 1. Idealized 3D geometries used for study phase II. Line i indicates unstented geometries; line ii, geometries with stent deployed along smaller daughter vessel; line iii, geometries with FDS deployed along larger daughter vessel; line iv, geometries used to study the effect of bifurcation angles, where $\alpha$ was varied while $\theta$ was kept constant at $120^{\circ}$.

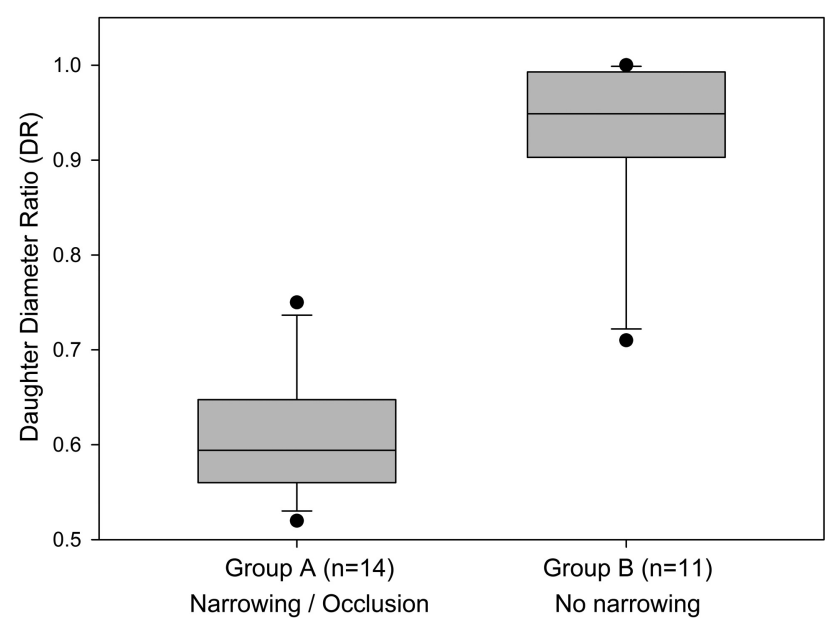

FIG 2. Whisker plot showing DR distribution within Group A (mean = $0.59 ; \mathrm{SD}=0.0766$ ), including datasets with events of partial (narrowing) or complete occlusion, and Group B (mean $=0.935, \mathrm{SD}=0.0823$ ), including datasets reporting no constriction (patency). Each boxplot describes first quartile values (bottom black line), median values (middle black line), and third quartile values (top black line). Error bars show minimum (bottom black bar) and maximum (top black bar) values. Solid circles denote outliers identified by using the maximum normed residual test. mond et al. ${ }^{15}$ These were set as resistance to flow rather than any a priori pressure or velocity value that might adversely affect, and overconstrain, posttreatment flow redistribution across the bifurcation. For the symmetric bifurcation case $(\mathrm{DR}=1)$, peripheral resistances where varied within typical physiologic ranges (50-60 $\mathrm{mm} \mathrm{Hg} \mathrm{s/mL)} \mathrm{encountered} \mathrm{at}$ MCA bifurcations as previously described by Reymond et $\mathrm{al}^{15}$ to study their influence on pre- and posttreatment hemodynamics.

\section{Phase III: Patient-Specific Computational Fluid Dynamics Study}

Six patient datasets were selected for the patient-specific computational fluid dynamics analyses, all representing cerebral bifurcations but with different levels of bifurcation asymmetry; these are cases 6, 7, and 22-25 in the On-line Table. The @neurIST computational tool chain was used for medical image segmentation and surface reconstruction. ${ }^{14,16}$ Blender was used for further surface mesh manipulation and refinement. Finally, surface meshes were superimposed on the original images for final check and validation.

Stents were virtually deployed by using the process described above along the same bifurcating vessel in accordance with clinical procedures. Computational analyses were performed following the same steady-state computational approach described for phase II, but with inlet boundary conditions set as average volumetric flow rate values (rather than diastolic and systolic flow rates as in phase II) to simulate the most representative flow condition at the bifurcation locations ${ }^{15}\left(\mathrm{Q}_{\mathrm{avg}}=1.25 \mathrm{~mL} / \mathrm{s}\right.$ for patients 6 and $24 ; \mathrm{Q}_{\mathrm{avg}}=2.3$ $\mathrm{mL} / \mathrm{s}$ for patients $7,22,23$, and 25 ).

\section{RESULTS}

\section{Phase I}

Fig 2 shows a box-and-whisker plot for the 25 datasets categorized as cases where FDS treatment had no vessel caliber change (Group $\mathrm{B}, n=11$ ) and cases where narrowing or sub-acute occlusion was observed either at baseline or at follow-up (Group A, $n=14$ ) and their correlation with daughter vessel DR. These distributions already show a marked correspondence between nonsymmetrical anatomies and vessel changes (Group A), with DR values between the first and third quartile centered on the nonsymmetrical region $\left(\mathrm{DR}_{\text {median }}=0.59 ; \mathrm{DR}_{1 \text { st quartile }}=0.52 ; \mathrm{DR}_{3 \text { rd quartile }}=0.65\right)$. Conversely, a marked correspondence was observed between symmetrical anatomies and lumen conservation, with DR values centered on the symmetrical region of $\mathrm{DR}=1\left(\mathrm{DR}_{\text {median }}=0.95\right.$; 

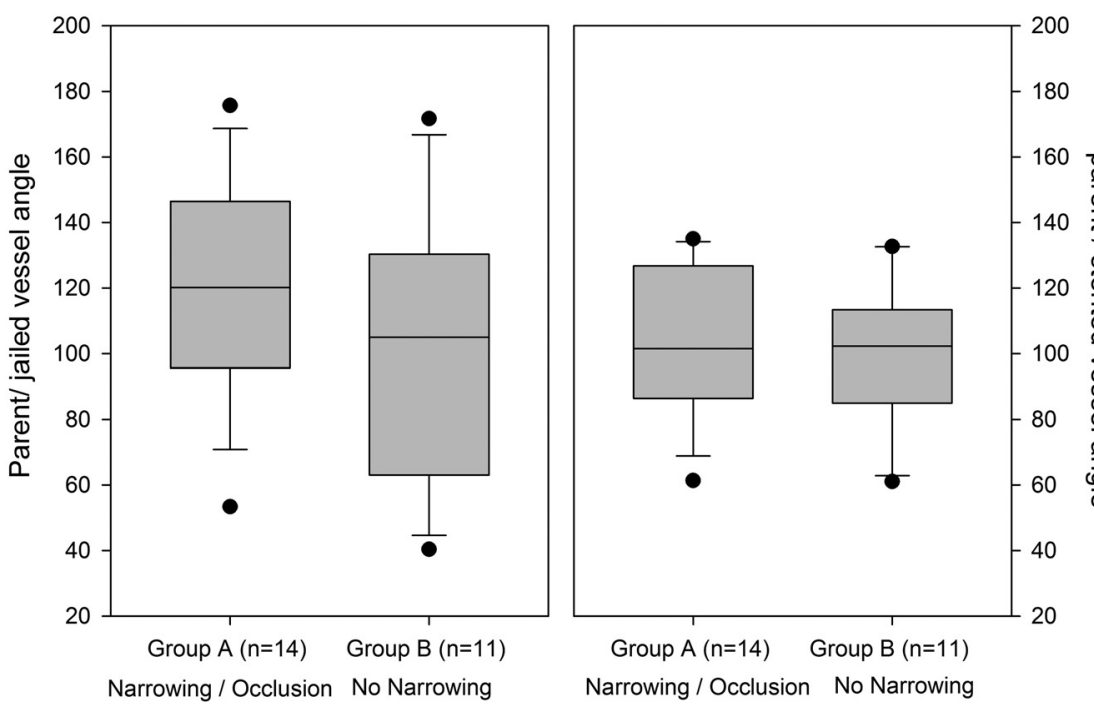

FIG 3. Whisker plots correlating DR with angles between parent and jailed vessel (left) and with angles between parent and stented vessel (right). Each boxplot describes first quartile values (bottom black line), median values (middle black line), and third quartile values (top black line). Error bars show minimum (bottom black bar) and maximum (top black bar) values. Solid circles denote outliers identified by using the maximum normed residual test.
$\mathrm{DR}_{1 \text { st quartile }}=0.91 ; \mathrm{DR}_{3 \mathrm{rd} \text { quartile }}=$ 0.99). A maximum normed residual test identified 1 outlier in each group. These outliers are represented in Fig 2. The $t$ test confirmed a statistically significant difference between the 2 groups' mean values, with $P$ values $\leq .001$. No correspondence of statistical significance was observed between angle measurements and artery diameter changes (Fig 3). The On-line Figure shows a percentage decrease in the diameter of the jailed daughter branch mostly distributed around $50 \%$.

\section{Phase II}

Computational results obtained for idealized anatomies are reported in Figs 4 and 5. Fig 4 shows space-averaged wall sheer stress (WSS) forces exerted by the flow of blood on the endothelial layer over the nonstented region of both daughter vessels at diastolic flow rates.
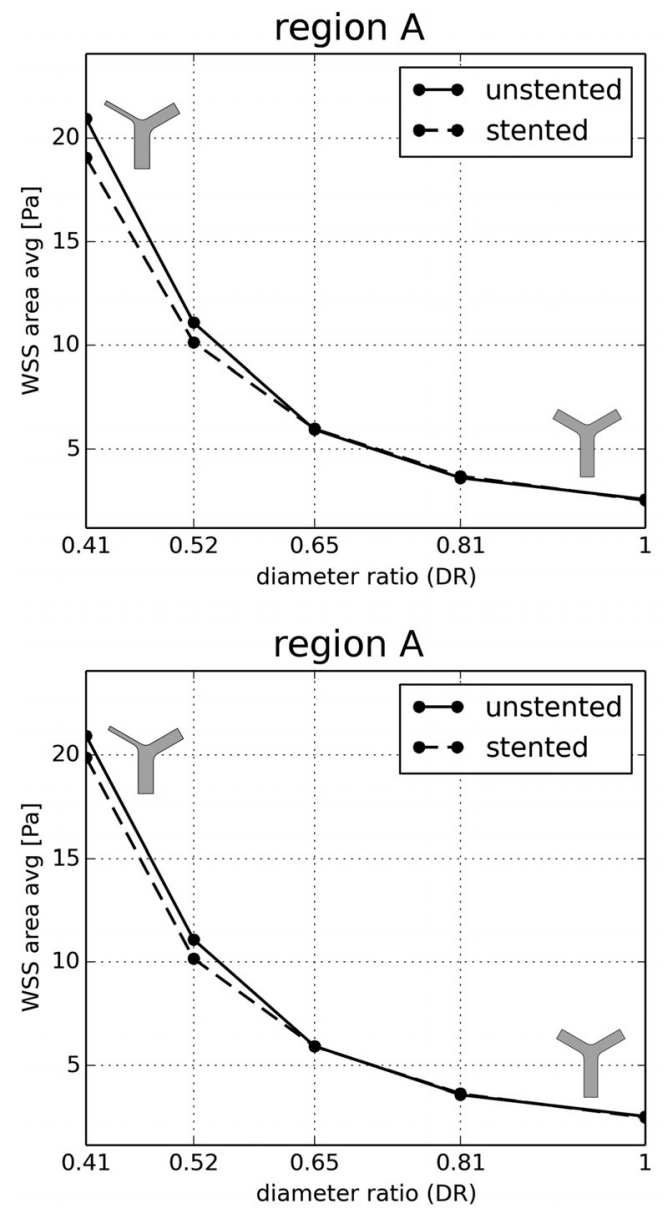
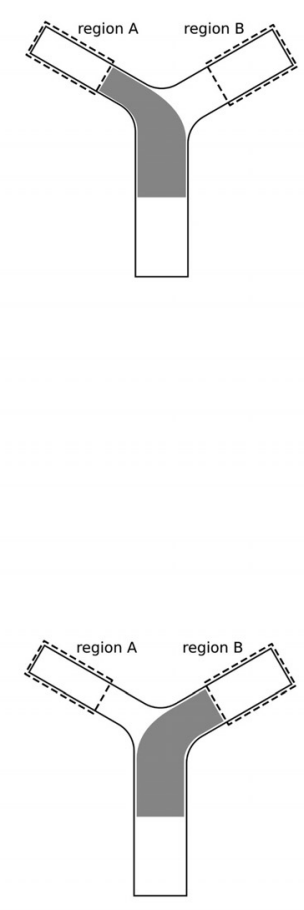

FIG 4. Space-average WSS calculated along the smaller daughter vessel (region A, left graphs) and larger daughter vessel (region B, right graphs) for diastolic volumetric flow rates $(0.98 \mathrm{~mL} / \mathrm{s})$ and 3 different configurations (solid lines, no stent; top graphs, dotted lines, stent along smaller vessel $\mathrm{d} 1$; bottom graphs, dotted lines, stent along larger vessel $\mathrm{d} 2$ ). 

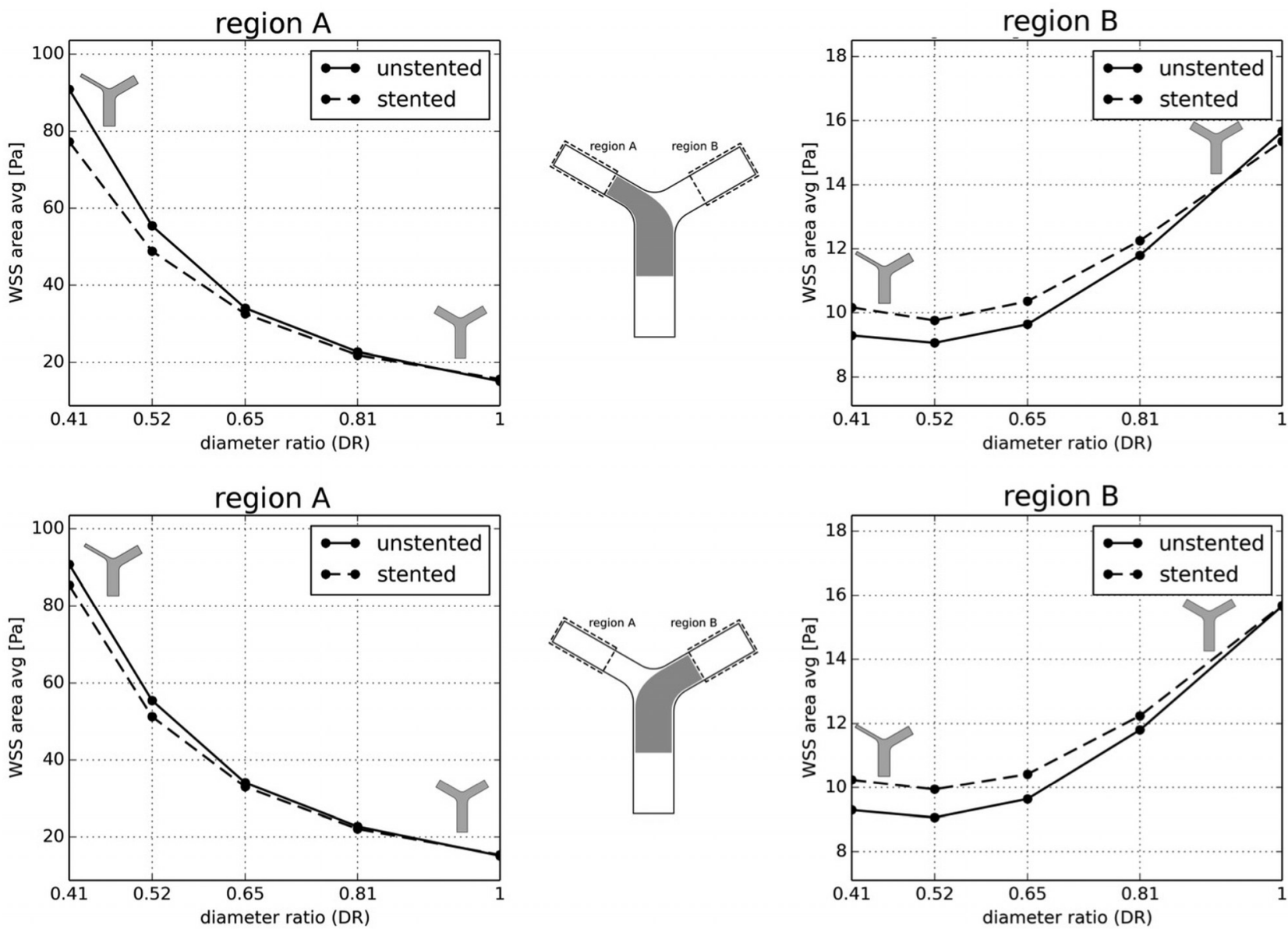

FIG 5. Space-average WSS calculated along the smaller daughter vessel (region A, left graphs) and larger daughter vessel (region B, right graphs) for peak systolic volumetric flow rates $(3.71 \mathrm{~mL} / \mathrm{s}$ ) and 3 different stent deployment configurations (solid lines, no stent; top graphs, dotted lines, stent along smaller vessel di; bottom graphs, dotted lines, stent along larger vessel d2).

WSS values computed over the smaller daughter vessel (Fig 4, region A) for both stent configurations show a $2 \mathrm{~Pa}(10 \%)$ decrease in WSS after stent deployment in nonsymmetric bifurcations $(\mathrm{DR}=0.41)$ and less pronounced changes when DRs approach symmetric values $(0.65<\mathrm{DR}<1)$. WSS calculated along the larger daughter vessel (Fig 4, region B) is less affected by the flow diverter, with changes in WSS values confined to less than 0.1 $\mathrm{Pa}(4 \%)$ across all ranges of DR values. Results for peak systolic flow rates (Fig 5) showed similar trends, with WSS fields mostly affected in nonsymmetrical bifurcations in both regions. Volumetric flow rates predicted at the daughter vessel outlets and pressures computed along the same vessels showed that stent deployment only marginally affects flow redistribution and pressure fields across the bifurcation, with maximum FDS-induced changes in flow rates of approximately $0.01 \mathrm{~mL} / \mathrm{s}$ and pressures of approximately $2 \mathrm{~mm} \mathrm{Hg}$ at peak systole. When we analyzed the influence of varying peripheral resistance within physiologic ranges and angles, we did not find any noticeable effect.

\section{Phase III}

Computational fluid dynamics results for patient-specific analysis are reported in the Table and Fig 6. In accordance with phase II observations, the patient-specific analysis showed how hemodynamic effects become larger when flow diverters are deployed in a

\begin{tabular}{|c|c|c|c|c|c|}
\hline \multirow[b]{2}{*}{ Patient } & \multirow[b]{2}{*}{ DR } & \multicolumn{2}{|c|}{$\begin{array}{l}\text { SP-AVG } \\
\text { WSS (Pa) }\end{array}$} & \multirow[b]{2}{*}{$\begin{array}{c}\% \\
\text { Difference }\end{array}$} & \multirow[b]{2}{*}{ Outcome } \\
\hline & & $\begin{array}{c}\text { No } \\
\text { Stent }\end{array}$ & Stent & & \\
\hline 6 & 0.71 & 16.8 & 16.8 & 0.0 & No narrowing \\
\hline 7 & 0.90 & 15.4 & 15.2 & -1.3 & No narrowing \\
\hline 22 & 0.47 & 7.2 & 6.8 & -5.6 & Narrowing \\
\hline 23 & 0.52 & 8.9 & 8.7 & -2.2 & Narrowing \\
\hline 24 & 0.90 & 1.9 & 1.9 & 0.0 & No narrowing \\
\hline 25 & 0.50 & 11.5 & 11.2 & -2.6 & Narrowing \\
\hline
\end{tabular}

Note:-SP-AVG indicates space-averaged.

nonsymmetrical configuration. Contour plots of WSS show some hemodynamic effect along the unstented daughter vessels for patients 22 and 25, where a decrease in WSS is qualitatively perceivable compared with the unstented configuration. A more quantitative analysis of the WSS space-averaged values over the same vessels is reported in the Table, with higher hemodynamic changes (decreased WSS) for the nonsymmetrical bifurcation and a comparatively smaller hemodynamic effect for the symmetric ones. The only exception is represented by patient 6 (Table), in whom a bifurcation with $\mathrm{DR}=0.7$ showed no hemodynamic differences between stented and unstented configurations. Patient 6 presented acute occlusion (the only case) and jailed vessel complete recanalization with preserved diameter at 3-month follow-up. 
Patient 6

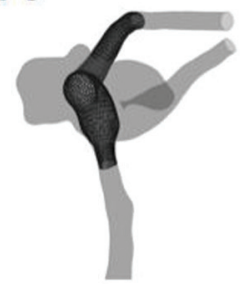

Patient 7

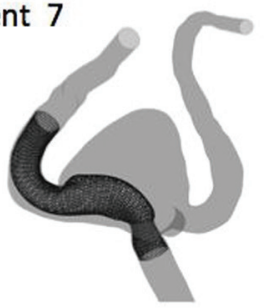

Patient 22

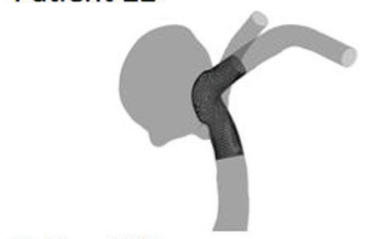

Patient 23

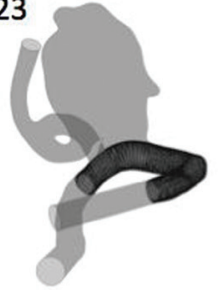

Patient 24

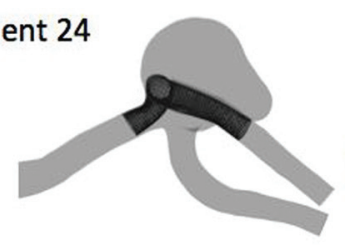

Patient 25

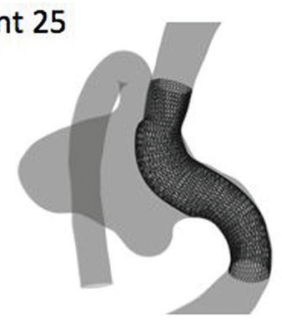

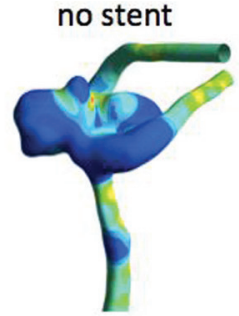
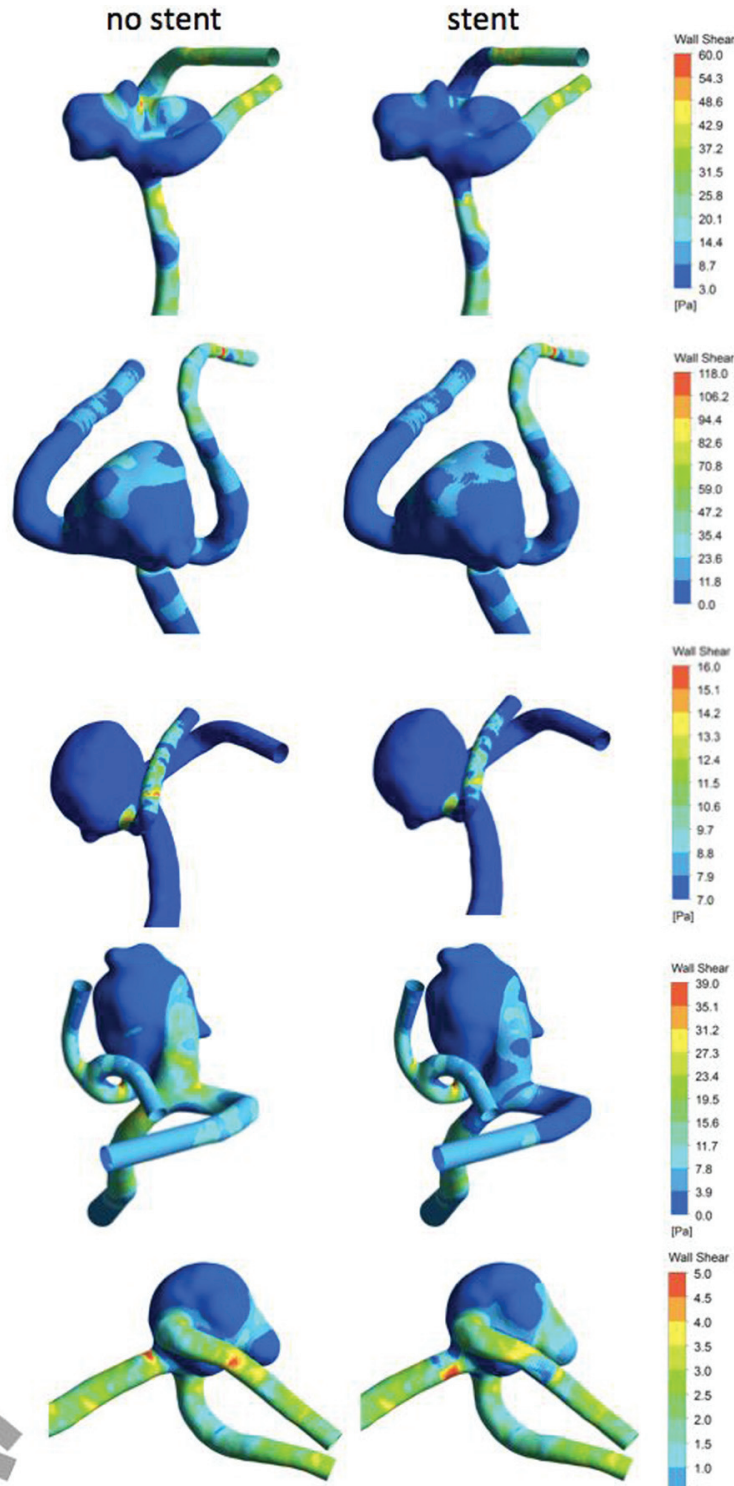

8.7
3.0
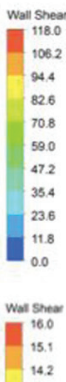

14.2
13.3
12.4

11.5

10.6

97
88

8.8
7.9

70

Wal Shear
39.0

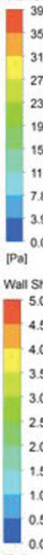

35.1
31.2

27.3
23.4

19.5

15.6

7.8
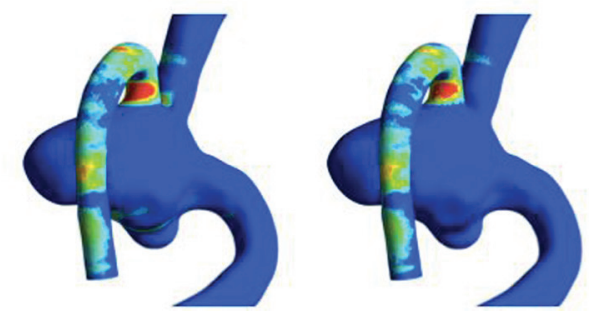

In the published series of bifurcation aneurysms treated with FDSs, approximately two-thirds of the arteries jailed by the FDS were affected by a narrowing process or complete subacute occlusion. ${ }^{3-8}$ In the 25 -aneurysm dataset reported in this study, narrowing or complete subacute occlusion was observed in $56 \%$ of cases. Only 1 patient (patient 6) presented acute arterial occlusion and complete artery recanalization at 3-month follow-up, keeping a normal diameter. The main hypothesis is that acute occlusion was caused by a thrombotic process because occlusion was immediate (during the procedure) and completely reversible. Occlusion and narrowing processes by permanent flow changes seem to be subacute events and not reversible.

Causes and mechanisms underlying FDS-induced artery caliber changes have not been elucidated. An analysis of anatomic and radiologic data for the study cohort reported here found a statistically significant correspondence between levels of bifurcation asymmetry and narrowing or subacute occlusion of the jailed artery. These correspondences were found for a 25-dataset cohort; a larger cohort size would be needed to enhance the significance of these findings.

Insertion of an FDS in asymmetric idealized bifurcations led to more changes in daughter vessel hemodynamics, in particular a reduction in WSS, compared with symmetric cases, regardless of whether the FDS was deployed along the larger or smaller branch. Deploying the FDS along the smaller bifurcating vessel led to more pronounced alterations in the hemodynamic parameters investigated. Patientspecific simulations confirmed previous results from the idealized geometry study, with observable hemodynamic changes in the asymmetric group. Although changes in WSS values seem

FIG 6. Computational fluid dynamics results for patient-specific analyses (phase III). WSS contours and anatomies were investigated.

\section{DISCUSSION}

Wide-neck bifurcation aneurysms present an unfavorable configuration for endovascular treatment. Balloon remodeling, stentassisted coiling, and other complex procedures such as doublestent placement are often applied to provide more support to coil packing, with permanent neurologic impairment estimated in approximately $10 \%$ of cases. ${ }^{5}$ A number of bifurcation aneurysms have been treated by using FDS procedures, and results are worse than in proximal aneurysms, with lower occlusion rates $(33 \%-$ 97\%) and higher permanent neurologic impairment (0\%-27\%). modest to definitely suggest a role played by hemodynamics, our findings have to be taken in a qualitative way and in view of the limitations of our approach. The computational fluid dynamics analysis was performed by using typical boundary conditions (eg, inlet flow rates). A more patient-specific approach would be necessary to fully understand in a quantitative way the significance of WSS alterations with respect to caliber changes and endothelial behavior. Nonetheless, the study identified an important trend demonstrating that hemodynamics is mostly perturbed by an FDS 
when deployed in a nonsymmetric bifurcation. It seems that changes in the forces to which endothelial cells are exposed may lead to vasomotor reaction in cerebral arteries. ${ }^{17-19}$ Considering that this study does not include biologic events analysis (eg, thrombosis) and in view of current knowledge, it is audacious to link small WSS changes to vasoconstriction as the main explanation. The role played by hemodynamics in the endothelial-mediated constrictive mechanisms needs further investigations.

The study of idealized cases identified a symmetry ratio threshold $(\mathrm{DR}=0.65)$ below which hemodynamic changes were noticeable. This threshold is similar to the value found in our 25-patient dataset that encompasses most cases within the group with narrowing or subacute occluding vessels (DR $<0.7)$. Further research and a statistically relevant number of datasets are necessary to fully validate and handle confidence in this association. However, this study affirmed the possibility that the phenomenon of FDS-induced vasoconstriction may be explained not only through the presence or absence of collateral vasculature, ${ }^{6,9}$ but also through changes induced on the local bifurcation hemodynamics.

As previously stated by Peach et $a{ }^{20},{ }^{20}$ successful use of an FDS in the treatment of intracranial aneurysms can only be achieved when the FDS creates sufficient resistance to flow entering the aneurysm so as to promote thrombosis while minimizing any alteration of the pre-existing hemodynamic stability and vessel homeostasis in the extra-aneurysm regions. We have found that hemodynamic changes were minimal when FDSs were deployed in symmetrical bifurcations and became progressively more significant as the level of asymmetry increased.

FDS-induced changes to flow and pressure were not significant, though alterations to local distributions of flow velocities were observed and justified changes in WSS. We only observed minor changes to pressure and flow redistribution upon stent deployment. This is somewhat in disagreement with other computational studies reported in the literature, ${ }^{21,22}$ where more significant alterations in flow and pressure data were observed between the unstented and stented configurations. This can be explained by the fact that in our approach, where we coupled the fluid solver to a $1 \mathrm{D}$ resistance model effectively imposing outlet pressure as a function of flow rate, we could impose, and keep constant, physiologically realistic values of peripheral resistance across our bifurcations. This guaranteed consistency on the imposition of peripheral resistance, which cannot be guaranteed by the imposition of constant pressure outlet boundary conditions because a different redistribution of flow, caused for example by the presence of a flow-diverting device, would lead to a different value of outlet resistance if pressure is maintained constant. The same findings are also somehow in disagreement with previously published data from experimental studies, where arguably peripheral resistance would have been kept constant. However, these studies do not provide any information on the peripheral resistances set for the experiment and only vaguely refer to the experimental model being connected to a "flow loop with flexible chloride tubing." 23,24 In these studies, the significant changes in pressure caused by the presence of low-porosity FDSs might have been affected by much lower than physiologic values of peripheral resistance, in the presence of which the local resistance of the FDS might be much greater and inevitably expected to induce large changes in flow redistribution and, therefore, pressure. We believe that our multidimensional resistance-based approach could offer a viable boundary condition option, other than pressurebased approaches, for the type of studies presented in this study, as also elegantly elucidated by Vignon-Clementel et al. ${ }^{25}$ However, a deeper understanding of the different physiologic conditions modeled by the 2 approaches and their suitability to investigate flow through stented bifurcation would require further research.

To evaluate the change in bifurcation angles that may have been induced by the deployment of a relatively stiff device, we studied the influence of angle changes on symmetrical idealized bifurcations without stents. This study did not produce noticeable changes in distal vessel hemodynamics to justify a subsequent study on the influence of angles on stented bifurcations. This is also confirmed by other studies reported in the literature. ${ }^{26,27}$

One might question the applicability of the theory identified by this study to sidewall arteries. Indeed, asymmetric bifurcations present similar anatomies to sidewall arteries, albeit with much higher percentages of parent arteries in the follow-up because ophthalmic and anterior choroidal arteries do not seem to suffer the same clinical fate when covered by FDSs. ${ }^{28,29}$ This could be explained by a different influence that peripheral vascular resistance has on local hemodynamics at different locations in the vascular network. Vascular resistance can be described as the impediment to blood flow in a vessel and is well described by the Hagen-Poiseuille relationship. This equation shows that resistance, or impediment to flow, increases with higher values of blood viscosity (hematocrit), vessel length, and smaller vessel radius. It should also be noted that, by far, the most important influence on resistance to flow is given by vessel radius, which appears to the power of 4 in this relationship. This strong influence of vessel radius on flow was one of the main reasons we decided to focus our study on reciprocal vessel diameters at bifurcations. In the systemic circulation, resistance to flow exerted by small peripheral vessels is known to have a significant influence on overall systemic blood flow. ${ }^{30}$ When we have studied the influence of peripheral resistance and varied it within physiologic ranges reported for MCA bifurcations, we have noticed little influence compared with the changes induced by FDS. This might not be the case at other vascular locations where the level of peripheral resistance is different. In fact, Reymond et $\mathrm{al}^{15}$ reported 2- to 3-fold higher values of peripheral resistance distal to the ophthalmic and choroidal arteries compared with known peripheral resistance after MCA bifurcations. It is therefore possible that the presence of an FDS in proximal vessels, which can also be considered as an impediment to flow, would not affect a flow that is predominantly dominated and influenced by a much higher peripheral resistance at these locations. This aspect requires further research to fully explain why FDS treatment at these locations does not seem to lead to vessel caliber changes.

\section{CONCLUSIONS}

This study identified a statistically significant correlation between nonsymmetrical bifurcations and narrowing or subacute occlusion in a patient dataset, showing that bifurcation anatomies below a certain level of symmetry $(\mathrm{DR}<0.65)$ are more likely to 
become narrower or occluded. A FDS induced modest hemodynamic changes (decreased WSS) when bifurcations were not symmetrical, but these were comparatively higher than those observed in symmetric bifurcations. Upon further research and clinical validation, this knowledge has the potential to guide and motivate further studies to reduce risk in complex aneurysm endovascular treatment, with the prospect of extending minimally invasive procedures to vascular regions that are currently deemed unsafe for FDS treatment.

Disclosures: Ignacio Larrabide-UNRELATED: Consultancy: Galgo Medical, Comments: development and validation of intracranial aneurysm treatment algorithms; Employment: CONICET, Comments: research fellow; Grants/Grants Pending: MINCYT, Comments: grant PICT 2015-0006*; Payment for Lectures Including Service on Speakers Bureaus: UNICEN, Comments: currently hold a position as lecturer at UNICEN. Christophe Cognard-UNRELATED: Consultancy: Stryker, Medtronic, Microvention. René Chapot—UNRELATED: Consultancy: Microvention, Medtronic, Stryker; Payment for Lectures Including Service on Speakers Bureaus: Microvention, Balt, Stryker, Medtronic, Siemens, Neuravi. Alberto Marzo—RELATED: Grant: Newton Fund Royal Academy of Engineering, Comments: grant funded traveling expenses to interact with researchers in Brazil on aspects of this grant*. *Money paid to the institution.

\section{REFERENCES}

1. Gonzalez AM, Narata AP, Yilmaz H, et al. Blood blister-like aneurysms: single center experience and systematic literature review. Eur J Radiol 2014;83:197-205 CrossRef Medline

2. Narata AP, Yilmaz H, Schaller K, et al. Flow-diverting stent for ruptured intracranial dissecting aneurysm of vertebral artery. Neurosurgery 2012;70:982-88; discussion 988-89 CrossRef Medline

3. Briganti F, Delehaye L, Leone G, et al. Flow diverter device for the treatment of small middle cerebral artery aneurysms. J Neurointerv Surg 2016;8:287-94 CrossRef Medline

4. Caroff J, Neki H, Mihalea C, et al. Flow diverter stents for the treatment of saccular middle cerebral artery bifurcation aneurysms. AJNR Am J Neuroradiol 2016;37:279-84 CrossRef Medline

5. Gawlitza M, Januel AC, Tall P, et al. Flow diversion treatment of complex bifurcation aneurysms beyond the circle of Willis: a single-center series with special emphasis on covered cortical branches and perforating arteries. J Neurointerv Surg 2016;8:481-87 CrossRef Medline

6. Saleme S, Iosif C, Ponomarjova S, et al. Flow-diverting stents for intracranial bifurcation aneurysm treatment. Neurosurgery 2014; 75:623-31 CrossRef Medline

7. Topcuoglu OM, Akgul E, Daglioglu E, et al. Flow diversion in middle cerebral artery aneurysms: is it really an all-purpose treatment? World Neurosurg 2016;87:317-27 CrossRef Medline

8. Yavuz K, Geyik S, Saatci I, et al. Endovascular treatment of middle cerebral artery aneurysms with flow modification with the use of the Pipeline embolization device. AJNR Am J Neuroradiol 2014;35: 529-35 CrossRef Medline

9. Iosif C, Berg P, Ponsonnard S, et al. Role of terminal and anastomotic circulation in the patency of arteries jailed by flow-diverting stents: animal flow model evaluation and preliminary results. J Neurosurg 2016;125:898-908 CrossRef Medline

10. Kallmes D, Hanel R, Lopes D, et al. International retrospective study of the Pipeline embolization device: a multicenter aneurysm treatment study. AJNR Am J Neuroradiol 2015;36:108-15 CrossRef Medline

11. Fung YC. Optimum design of blood vessel bifurcation. In: Biomechanics: Circulation. New York: Springer-Verlag; 1997:118-25

12. Larrabide I, Kim M, Augsburger L, et al. Fast virtual deployment of self-expandable stents: method and in vitro evaluation for intracra- nial aneurysmal stenting. Med Image Anal 2012;16:721-30 CrossRef Medline

13. Bernardini A, Larrabide I, Morales HG, et al. Influence of different computational approaches for stent deployment on cerebral aneurysm haemodynamics. Interface Focus 2011;1:338-48 CrossRef Medline

14. Villa-Uriol MC, Berti G, Hose DR, et al. @neurIST complex information processing toolchain for the integrated management of cerebral aneurysms. Interface Focus 2011;1:308-19 CrossRef Medline

15. Reymond P, Bohraus Y, Perren F, et al. Validation of a patient-specific one-dimensional model of the systemic arterial tree. Am J Physiol Heart Circ Physiol 2011;301:H1173-82 CrossRef Medline

16. Marzo A, Singh P, Reymond P, et al. Influence of inlet boundary conditions on the local haemodynamics of intracranial aneurysms. Comput Methods Biomech Biomed Engin 2009;12:431-44 CrossRef Medline

17. Bryan RM Jr., Marrelli SP, Steenberg ML, et al. Effects of luminal shear stress on cerebral arteries and arterioles. Am J Physiol Heart Circ Physiol 2001;280:H2011-22 Medline

18. Heistad DD. What's new in the cerebral microcirculation? Landis Award lecture. Microcirculation 2001;8:365-75 CrossRef Medline

19. Koller A, Toth P. Contribution of flow-dependent vasomotor mechanisms to the autoregulation of cerebral blood flow. J Vasc Res 2012; 49:375-89 CrossRef Medline

20. Peach TW, Spranger K, Ventikos Y. Towards predicting patient-specific flow-diverter treatment outcomes for bifurcation aneurysms: from implantation rehearsal to virtual angiograms. Ann Biomed Eng 2016;44:99-111 CrossRef Medline

21. Tang AY, Chung WC, Liu ET, et al. Computational fluid dynamics study of bifurcation aneurysms treated with Pipeline embolization device: side branch diameter study. J Med Biol Eng 2015;35:293-304 CrossRef Medline

22. Kono K, Terada T. Hemodynamics of $\mathbf{8}$ different configurations of stenting for bifurcation aneurysms. AJNR Am J Neuroradiol 2013; 34:1980-86 CrossRef Medline

23. Roszelle BN, Babiker MH, Hafner $\mathrm{W}$, et al. In vitro and in silico study of intracranial stent treatment for cerebral aneurysms: effects on perforating vessel flows. J NeuroIntervent Surg 2013;5:354-60 CrossRef Medline

24. Roszelle BN, Gonzalez LF, Babiker MH, et al. Flow diverter effect on cerebral aneurysm hemodynamics: an in vitro comparison of telescoping stents and the Pipeline. Neuroradiology 2013;55:751-58 CrossRef Medline

25. Vignon-Clementel IE, Figueroa CA, Jansen KE, et al. Outflow boundary conditions for three-dimensional finite element modeling of blood flow and pressure in arteries. Comput Methods Appl Mech Eng 2006;195:3776-96 CrossRef

26. Beier S, Ormiston J, Webster M, et al. Impact of bifurcation angle and other anatomical characteristics on blood flow - a computational study of non-stented and stented coronary arteries.J Biomech 2016;49:1570-82 CrossRef Medline

27. Farnoush A, Avolio A, Qian Y. Effect of bifurcation angle configuration and ratio of daughter diameters on hemodynamics of bifurcation aneurysms. AJNR Am J Neuroradiol 2013;34:391-96 CrossRef Medline

28. Kühn AL, Hou SY, Perras M, et al. Flow diverter stents for unruptured saccular anterior circulation perforating artery aneurysms: safety, efficacy, and short-term follow-up. J Neurointerv Surg 2015; 7:634-40 CrossRef Medline

29. Neki H, Caroff J, Jittapiromsak P, et al. Patency of the anterior choroidal artery covered with a flow-diverter stent. J Neurosurg 2015; 123:1540-45 CrossRef Medline

30. Guyton A, Hall J. Textbook of Medical Physiology. 13th ed. Philadelphia: Sanders Elsevier; 2011:195-96 